\title{
REV ISTA
}

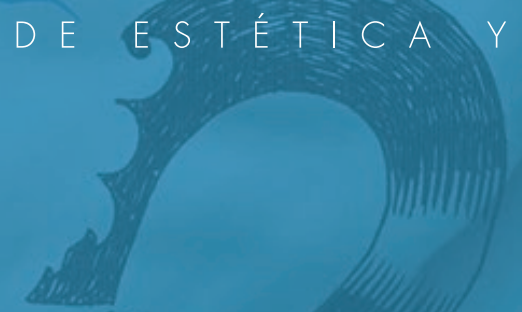

TEORIA

$D E$

LAS

A RTES

No $4 \cdot 2017 \cdot$ ISSN $2386-8449$

\section{CONVERSANDO CON}

"Más allá, pero aquí mismo", Entrevista con José Jiménez, por Miguel Salmerón Infante

UT PICTURA POESIS

Apuntes (1993-1998), Antonio Campillo

Dichoso aquel que no tiene patria, Poemas de Hannah Arendt, versiones de Anacleto Ferrer

PANOORAMA: ESTÉTICA DE LAS CREACIONES ESCÉNICAS Sección coordinada por Antonio Notario Ruiz

TEXTO INVITADO: O silêncio do tempo do silêncio, Fernando José Pereira

TEXTO. INVITADO: Ética y poética en el juego teatral de Reikiavik de Juan Mayorga, Zoe Martín Lago

El problema de la autonomía del teatro, Adrián Pradier Sebastián

¿Qué hubiera sido de Edipo sin Aristóteles y sin Freud? Sebastián Gámez Millán

Como actores en el gran teatro del mundo, Roger Ferrer Ventosa

Mahagonny: surrealismo y dialéctica de la anarquía. Apuntes desde T.W. Adorno, Marcelo Jaume Teruel

Nauman, Mirecka, Rainer: entre el cuerpo y el signo, Laura Maillo Palma

El espacio relativo de Newton y la trasformación de las prácticas escénicas en el teatro moderno, Raúl Pérez Andrade

Sturm und Drang. El drama del genio y Shakespeare, Milagros García Vázquez

MISCELÁNEA

Velázquez y el origen de la modernidad filosófica, Carlos M. Madrid Casado

Duchamp según Jean Clair vs. Arthur Danto, a 100 años de la Fuente, Andrea Carriquiry

Alegoría barroca e imagen dialéctica: el esfuerzo de Walter Benjamin y Theodor W. Adorno para pensar la dialéctica de la naturaleza y la forma estética, Vanessa Vidal Mayor

La idea de tradición en la estética de Jan Mukařovský, Raúl Sanz García

De la visión y el espanto: el tacto suspendido y la experiencia ante el límite, Rayiv David Torres Sánchez

Desrealizando el mundo objetivo: sobre la inmanencia de lo artístico en la fenomenología estética de M. Henry, Jaime Llorente Cardo

Estudios Visuales. Giros entre la crítica de la representación y la ciencia de la imagen, Sergio Martínez Luna

Épica en el arte: el caso de la cảnción de autor, Gustavo Sierra Fernández

El cine más allá de la narración de Lisandro Alonso, Horacio Muñoz Fernández

Perdidos en la isla de los prodigios: Lost o el abismo alegórico del drama barroco, Ainhoa Kaiero Clave

RESENAS

EDITA

\section{SEyTA.}

SOCIEDAD ESPAÑOLA
DE ESTETICAY TEORIA DE LAS ARTES 


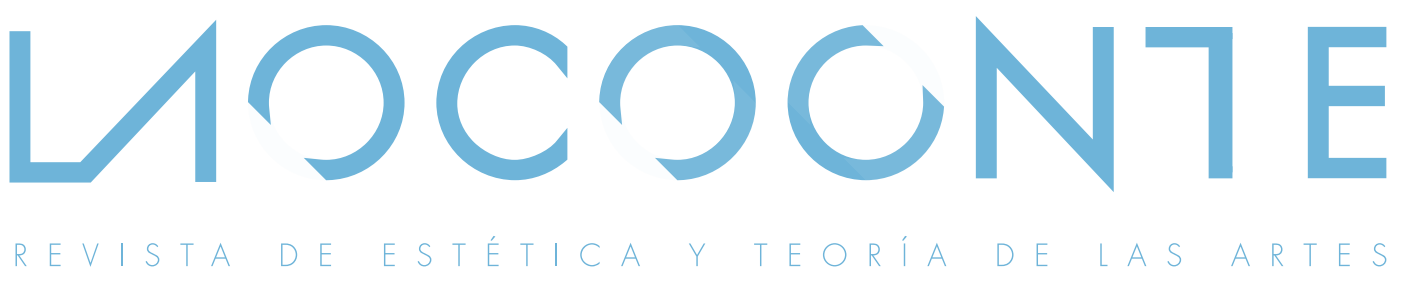

$\mathrm{N}^{\circ} 4 \cdot 2017$

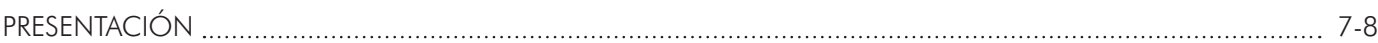

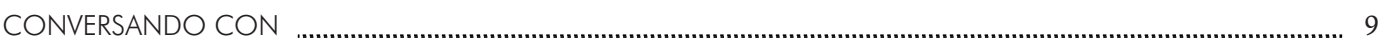

"Más allá, pero aquí mismo", Entrevista con José Jiménez, por Miguel Salmerón Infante .......................... 11-21

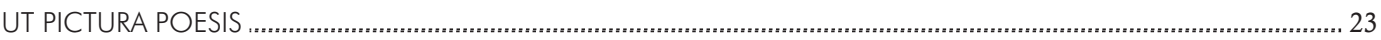

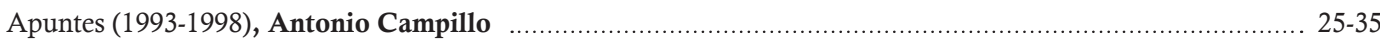

Dichoso aquel que no tiene patria, Poemas de Hannah Arendt, versiones de Anacleto Ferrer .............................. 37-49

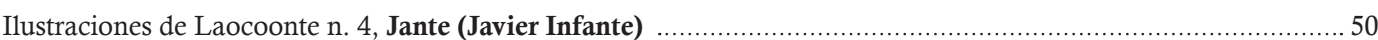

PANORAMA

ESTÉTICA DE LAS CREACIONES ESCÉNICAS _. _ _ _ _. sil

¿Qué hubiera pensado Wagner? Antonio Notario Ruiz (Coordinador) .......................................................... 53-55

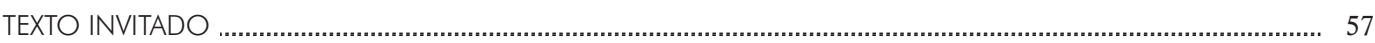

O silêncio do tempo do silêncio, Fernando José Pereira …....................................................................... 59-63

Ética y poética en el juego teatral de Reikiavik de Juan Mayorga, Zoe Martín Lago …..................................... 64-72

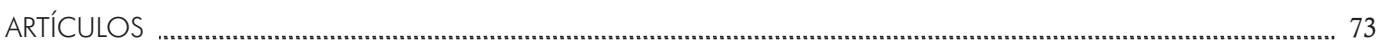

El problema de la autonomía del teatro, Adrián Pradier Sebastián . ....................................................... 75-92

¿Qué hubiera sido de Edipo sin Aristóteles y sin Freud? Sebastián Gámez Millán ........................................ 93-108

Como actores en el gran teatro del mundo, Roger Ferrer Ventosa ........................................................ 109-125

Mahagonny: surrealismo y dialéctica de la anarquía. Apuntes desde T.W. Adorno, Marcelo Jaume.Teruel... 126-133

Nauman, Mirecka, Rainer: entre el cuerpo y el signo, Laura Maillo Palma ............................................. 134-145

El espacio relativo de Newton y la trasformación de las prácticas escénicas en el teatro moderno,

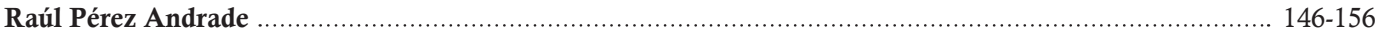

Sturm und Drang. El drama del genio y Shakespeare, Milagros García Vázquez ...................................... 157-168

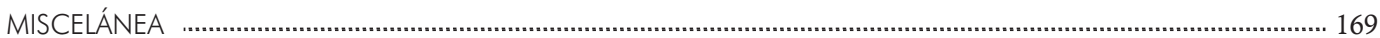

Velázquez y el origen de la modernidad filosófica, Carlos M. Madrid Casado .......................................... 171-181

Duchamp según Jean Clair vs. Arthur Danto, a 100 años de la Fuente, Andrea Carriquiry _ 18.…………... 182-198

Alegoría barroca e imagen dialéctica: el esfuerzo de Walter Benjamin y Theodor W. Adorno para pensar la dialéctica de la naturaleza y la forma estética, Vanessa Vidal Mayor .................................................... 199-213

La idea de tradición en la estética de Jan Mukařovský, Raúl Sanz García ................................................... 214-231

De la visión y el espanto: el tacto suspendido y la experiencia ante el límite, Rayiv David Torres Sánchez .... 232-240

Desrealizando el mundo objetivo: sobre la inmanencia de lo artístico en la fenomenología estética

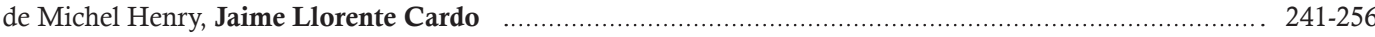


Estudios Visuales. Giros entre la crítica de la representación y la ciencia de la imagen,

Sergio Martínez Luna

Épica en el arte: el caso de la canción de autor, Gustavo Sierra Fernández

El cine más allá de la narración de Lisandro Alonso, Horacio Muñoz Fernández

Perdidos en la isla de los prodigios: Lost o el abismo alegórico del drama barroco, Ainhoa Kaiero Claver

RESEÑAS

Teorías del arte desde el siglo XXI, Pedro Lecanda Jiménez-Alfaro

Rimada Botánica, Xaverio Ballester

Sobre ciudades y arquitecturas, Jürgen Misch

Esbozo de una amistad sempiterna. Sobre Fuster y Alfaro, Raquel Baixauli

Cómo se analiza una obra de teatro, Teresa Aguado Garzón

Vuelan las imágenes, Verónica Perales Blanco

Mudanzas Espacio-temporales. Imagen y memoria, Raimon Ribera

$342-345$

Qué quieren las imágenes? Una crítica a la cultura visual, Esther González Gea

346-349

Zoos humanos, ethnic freaks y exhibiciones etnológicas, Lurdes Valls Crespo

350-353

España de la Guerra, Amanda del Rey Mateos

354-356

Benjamin, Barthes y la singularidad de la fotografía, Jorge Martínez Alcaide

$357-360$

Arte escrita: texto, imagen y género en el arte contemporáneo, Óscar Ortega Ruiz

$361-363$

Sobre el futuro del estudio del pasado, Ana Meléndez 364-366

Conducir a una diosa, Sergio Requejo Pérez

367-370

Cioran en los Archives paradoxales. (Tome III), Joan M. Marín

Género, memoria y cultura visual en el primer franquismo, Raquel Baixauli

La eternidad de un día, Carmen Martínez Sáez

Lo diabólico, lo demónico, lo fáustico en la literatura, la música y el arte, Mauro Jiménez

Circuit Circus. Circo, Intelectuales y Payasos, Ricard Silvestre

Ilustraciones de Jante (Javier Infante).

Fotografía de portada de Tamara Djermanovic intervenida con ilustración de Jante (Javier Infante). 


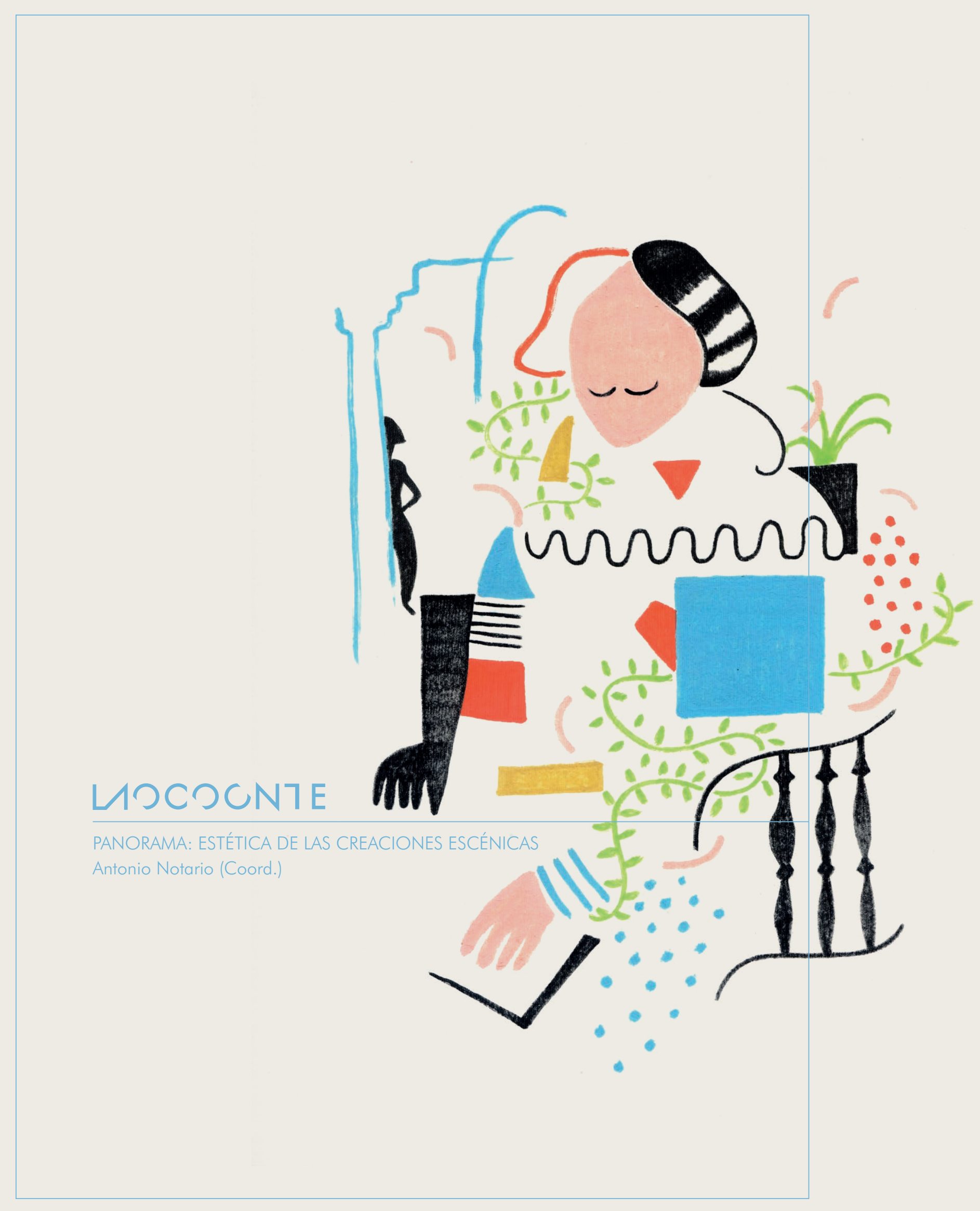




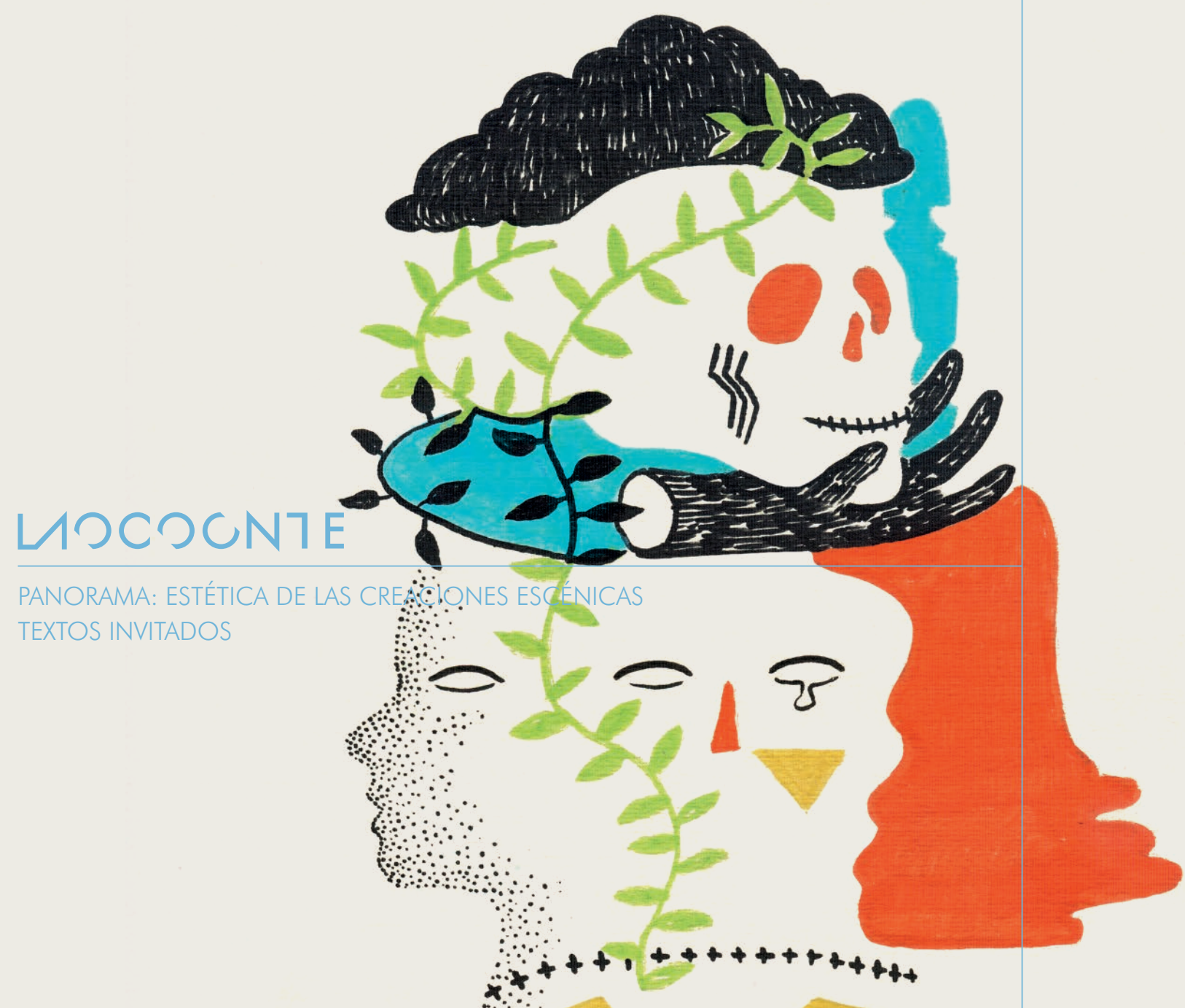




\title{
O silêncio do tempo do silêncio
}

\author{
The silence of time of silence
}

\author{
Fernando José Pereira, I2ADS/FBAUP*
}

\section{Resumo}

Dizia-me um amigo, entretanto falecido, que não seriam necessários mais 10 anos para se ter que comprar o silêncio. Não foram precisos, de facto, tantos anos. Aqui estamos em pleno tempo de ausência absoluta do silêncio. O texto tenta questionar o silêncio de forma aparentemente paradoxal, isto é, desde o interior do território das artes visuais. Falar do silêncio como ausência. Como é afirmado no texto: A sombra é, quero crer, uma outra forma de silêncio, desta feita, cromático.

Palavras-chave: silencio, tempo.

\begin{abstract}
I was told by a friend, in the meantime deceased, that it would not take another 10 years to have to buy silence. In fact, it was not necessary so many years. Here we are in a time of absolute absence of silence. The text tries to question the silence in an apparently paradoxical way, that is, from within the territory of the visual arts. Talking about silence as absence. As stated in the text: The shadow is, I would believe, another form of silence, a chromatic one.
\end{abstract}

Keywords: silence, time.

No espectáculo em que se transformou o quotidiano ou, se quisermos, no espectáculo quotidiano do presente, a regra operativa dominante é gritar o mais alto possível: desde um artista qualquer que tudo faz, naturalmente nos termos reconhecidos pelo espectáculo, para que a sua voz seja ouvida mais alto que a realidade que quer tratar - os refugiados a chegarem à Europa; passando por uma qualquer cena parlamentar brasileira em que um qualquer deputado grita mais alto que o anterior os porquês do seu voto, à constatação assustadora da demência e surdez profunda de alguns membros de uma banda rock qualquer, até à realidade qualquer de um ser qualquer que incomoda toda a gente numa carruagem de metro com as suas músicas de telemóvel em desafio contínuo com outro ser qualquer que ininterruptamente deixa o seu telefone assobiar um som qualquer para anunciar uma qualquer mensagem.

Nada de especial, pois; qualquer coisa, mas que se faça sentir, sobretudo, que se faça ouvir, em sentido literal ou metafórico, tanto faz.

Este é um retrato possível do nosso mundo de tempos comprimidos e de comportamentos previsíveis e adaptáveis: quaisquer, portanto!

E, contudo, uma leitura de sentir mais agambeniana entra em conflito directo com estas situações. O ser qualquer da comunidade que vem de Agamben é deliberadamente

* Facultad de Bellas Artes, Universidad de Oporto, Portugal.efejotape@me.com 
esvaziado de características identitárias exactamente para poder, debaixo do seu anonimato, produzir a alternativa possível...e, naturalmente, silenciosa. Encontramonos, então, perante um paradoxo evidente.

Ou não?

O capitalismo global e tecnológico soube explorar esta dimensão com uma precisão cirúrgica ao intrometer-se descaradamente na relação entre o eu e o Outro, primeiro virtualizando-a e logo de seguida invertendo-a, quer dizer, tornando toda a relação numa espécie de diálogo especular entre o mesmo. Um selfie diálogo, isto é, um não diálogo, um monólogo acompanhado. Esta constatação é da máxima importância pois potencia a resolução do aparente paradoxo em que nos encontramos: ao promover a primazia do eu em absoluto, a tecnologia digital introduziu uma realidade falaciosa e, sobretudo, perigosa: todos deixamos, de repente, de ser anónimos, embora continuemos qualquer. Ou seja, teremos todos, a partir de agora, um grupo, quanto maior melhor, que nos escuta, quer dizer, que se escuta a si próprio, mas isso, naturalmente não basta. A luta é sempre pela primazia - quantos amigos tens no facebook? - e, para tal, o que fazer: gritar o mais alto possível. A gritaria actual potenciou uma cacofonia de muito altos decibéis.

O que fazer, então?

Dizia Mario Perniola num belo livro publicado já há alguns anos que, mais interessante que a luz que irradia dos spotlights é a sombra que a partir deles é projectada. A sombra é, quero crer, uma outra forma de silêncio, desta feita, cromático.

A proposta desanestésica ${ }^{1}$ que venho defendendo ao longo dos últimos anos como possibilidade conceptual de trabalho artístico contém no seu âmago uma apelo a esta zona sombria. Um estar presente nos termos desafiantes da necessidade de aprofundamento. Um deliberado afastamento da cumplicidade amável da imagética global, o que quererá dizer, um silêncio como opção, por oposição à gritaria cacofónica das opções comunicativas da pandemia global das imagens. - só assim agora se é amável, veja-se a necessária gritaria decibélica de uma qualquer loja de centro comercial como forma comum de cativar os clientes.

Uma estrutura complexa do saber na produção das imagens, ou seja, uma espécie de silêncio que emerge da obra na sua opacidade, como aquele que é possível fruir a níveis profundos debaixo de água; Um silêncio que activa os segredos e os enigmas que são oferecidos à desocultação pelos artistas.

$\mathrm{E}$, finalmente, uma necessária conservação do tempo que convide à reflexão².

1 A palavra desanestesia é formada pela junção do prefixo des à palavra anestesia. Esta significa originalmente a negação da beleza aísthesis, mais recentemente viu-se vulgarizada como anulação da dor. A noção de desanestesia tenta corporizar no seu jogo de significações uma aproximação aos dois conceitos anteriores. A colocação do prefixo des contraria, contudo, a direç̧ão significativa a que se propõe, isto é, revela a apologia da crueza, e não o contrário. Uma tentativa de aproximação ao real.

2 Paragem, aragem, agem, todas estas palavras se encontram na construção que dá título a um vídeo que realizei no já distante ano de 2007 e cujo título é "para-age-(m)". Conduzem, é certo, para uma ideia de paradoxal convivência mas é exactamente na construção do oximoro que quero situar o conjunto de imagens/movimento que apresenta.

O nosso tempo consome o tempo de forma rápida e impiedosa e, talvez por essa razão, cada vez temos menos tempo para ter tempo. A alteração que está a ser produzida na temporalidade contemporânea nomeadamente através da catadupa de imagens em que estamos literalmente mergulhados produziu uma inversão conceptual que merece atenção: o estar parado potencia a acção. Esta espécie de passividade radical é amplamente experienciada no recurso da contemplação das imagens.

As imagens produzidas pela comunicação sucedem-se de forma cada vez mais veloz (pensemos na imposição da 
Uma proposta que, ao corporizar-se no complexo relacionamento dialéctico dos vários itens que a compõem, se apresenta longe da esquizofrenia social instalada, porque reconhece os elos da temporalidade e compõe-se, naturalmente diria, de camadas silenciosas de tudo o que seja necessário para se compreender a si própria como elemento determinante e, contudo, minoritário, de uma narrativa outra, que conhece o tempo e o silêncio, isto é o saber.

Um posicionamento que resgata o passado como força motriz para o entendimento do presente - disse Fernando Rosas na sua última aula que a nossa é uma época da desmemorização. O preenchimento significacional das várias camadas do tempo que corporizam a obra de arte oferecem-se em múltiplas formas. Talvez a mais adequada ao nosso tempo seja sob a forma do espectral. Um corporizar silencioso e talvez assombrado,- a sombra outra vez -, de um reviver ontológico do tempo, agora sobre a forma silenciosa da activação da memória.

Não há obra sem tempo e uma obra habitada por esse silêncio espectral que é a presença da temporalidade complexa que compreende o passado, o presente e, também, o futuro é, de certeza uma obra politizada, pois reconhece, como diria Fredric Jameson a sua cartografia cognitiva e, ao fazê-lo, posiciona-se perante a pandemia. Refugia-se na sombra, isto é no silêncio.

Existe, portanto, uma outra arte para lá do espectáculo e da berraria cacofónica do presente. Uma arte que se introduz subrepticiamente num amplo território deliberadamente silencioso e, por isso, da maior importância, e que se encontra compreendido em forma inexterior ${ }^{3}$ à condição polar que determina a expansividade global e a sua congénere negativa.

Uma arte em metáfora Cageana de 4.33 que procura o seu protagonismo no outro lado da vibração formal, que sabe escutar e ver, porque não, o silêncio.

Mas sejamos claros. Não se trata aqui de nenhuma deriva new age que tanto contribui, também, para o espectáculo global da diversidade homogeneizada. Não. Trata-se, antes, de um posicionamento politizado que reconhece no seu fazer saber uma distância compulsiva que o situa cartograficamente, - importante a possibilidade de Hal Foster de uma parallactic view -, um mapeamento silencioso, por opção, que permite a necessária distância crítica potenciadora dos significados esclarecidos. Escrevi há muitos anos que o mais interessante da condição do exilado é a possibilidade de ver de fora. Um ver que é silencioso, pois não consegue penetrar a barreira fronteiriça da cacofonia mas que, nem por isso, deixa de ser determinante pois afirma-se em continuada temporalidade, uma espécie de resistência que se corporiza como contemplação activa, isto é, lenta, longa e silenciosa. Hoje, em tempos de totalização global e de compulsiva internalização, o exílio é conceptual. Porventura, a melhor forma de, em tonalidades derridianas $^{4}$, introduzirmos essa necessária condição de positividade na noção, é

MTV para a realização dos videoclips: tempo máximo de cada plano 5 segundos) e uma das respostas possíveis passa pelo recurso a uma contemplação, digamos, estratégica para podermos distanciarmo-nos da noção tão criticada durante toda a modernidade. A contemplação que aqui se propõe passa pelo ajuste temporal à acção de pensar e, como todos sabemos, esse acto reflexivo leva tempo. Ao tornar necessário o tempo como factor determinante para o agir estamos a possibilitar uma nova forma de observar: a contemplação activa. Quer dizer, uma possibilidade de inserir o factor atenção no âmbito do consumo das imagens, isto é, transformar a deriva superficial da dromologia nesse investimento estranho ao nosso tempo que é a paragem.

3 de inexterioridade, isto é, de um necessário distanciamento crítico, contudo, tornado compulsivamente interior.

4 Disse uma vez Derrida, em entrevista ao jornal catalão La Vanguardia, que a palavra impossível pode possuir uma 
entendê-la segundo uma possibilidade da impossibilidade, uma opção em aberto para trabalho em tempos e realidades adversas. O silêncio, na sua configuração alegórica, aquela que nos interessa, apresenta, então, essa im-possibilidade de actuar no interior compulsivo.

A formalização do vazio que a arte tenta na sua aproximação ao real ${ }^{5}$ é, afinal, o silêncio numa outra enunciação, talvez mais arquétipa e descarnada, mas ainda assim, mais verdadeira na construção de si própria e da relação intensa que ambiciona ter com a realidade que a constrói. É aí, nessa fronteira que se encontra o limite, aquele que produz a modificação estruturante que potencia a arte como possibilidade. Onde o espaço liso do silêncio encontra a visualização das suas rogosidades e estas o afirmam como potência da impotência, afinal, a força que imana e que ressoa, obviamente, de forma silenciosa e que, por isso mesmo, nos permite afirmar a individualidade de tal gesto: opaco, por certo, silencioso, sem dúvida e, contudo, impactante, à sua maneira, porque assim se permite.

Refere Byung-Chul Han num livro ainda pouco conhecido por cá:

Ao contrário do shock (benjaminiano), o punctum (barthiano) não grita. O punctum ama o silêncio, conserva o segredo. Apesar do seu silêncio pronuncia-se como ferida. Uma vez que se aboliram todos os significados, todas as intenções, todas as opiniões, todas as valorizações, todos os juízos, todas as encenações, todas as poses, todos os gestos, todas as codificações e todas as informações, o punctum revela-se como um resto permanente, como um resto que entoa a sua canção e nos consterna. O punctum é o restante resistente que fica após a representação, o imediato que se subtrai à transmissão por meio de sentido e significação; é o corporal, o material, o afectivo, o inconsciente; é mais, é o real que se opõe ao simbólico. ${ }^{6}$

É, por isso, a obra que não é cúmplice, que é dissensão e, contudo, não precisa do o gritar. O seu silêncio é constitutivo e isso é a sua condição mais preciosa.

Não é muito, mas também não é pouco, a mim chega-me.

\section{Pósfacio}

Acabo de chegar de Münster na Alemanha, onde estive a visitar a $5^{\text {a }}$ edição dos "Skupltur Projekts". Há algo de incomum nesta iniciativa que tem a ver com a sua relação com o tempo. Realiza-se apenas de 10 em 10 anos, o que é uma mais valia evidente e, contudo, na minha terceira visita, um certo vazio apoderou-se do meu pensamento relativamente às obras vistas. Trata-se de um vazio - silêncio - que é defensivo, que potencia uma recusa. Aquela que advém do cansaço das imagens, dessa espécie de pandemia em que fomos compulsivamente envolvidos e que nos faz parar. O excesso de imagens, no corpo, nas cidades, nos telemóveis, nas televisões, por todo o lado... está a fazer crescer essa necessidade premente de uma hipótese de saída. Não qualquer hipótese moralista de algo hipoteticamente melhor, antes, a corporização de possibilidades de trabalho que neste interior compulsivo possam inscrever a sua

outra conotação, agora, de positividade. A alteração lexical para im-possível permite, segundo este pensador, a mutação proposta. O im-possível é a condição de possibilidade do acontecimento e da escrita. Da arte, também, acrescentamos nós. A única possibilidade de algo é a sua experiência de impossibilidade.

5 Aqui na significação lacaniana do termo, isto é, na sua impossibilidade simbólica.

6 Han, Byung-Chul, La salvación de lo bello. Trad. Alebrto Ciria. Barcelona, Herder, 2015, pp. 57 - 58. 
presença silenciosa. Um silêncio que, como afirma Mário Azevedo, potencia no seu interior as várias possibilidades da dissensão, do escape à captura e, acima de tudo, da manutenção, mesmo que em agonia incessante, de uma continuidade para o fazer saber da arte. Longe dos formalismos pós-críticos que hoje nos querem fazer crer ser o zeitgeist e em plena consciência das dificuldades que emergem de forma desmesurada nestes, assim chamados por Hal Foster, bad new days. Ou seja, num declarado posicionamento político que afirme o gesto artístico como uma espécie de grito silencioso que nos permita, de novo, fruir as obras sem cansaço. Escutar o que elas nos dizem, com toda a atenção, com o tempo necessário. Não é pedir muito, também não será pouco. A mim, mais uma vez, chega-me. 